\title{
Exergy and economic analysis of organic rankine cycle hybrid system utilizing biogas and solar energy in rural area of China
}

\author{
Zhao, Chunhua; Zheng, Siyu; Zhang, Ji; Zhang, Yangjun
}

Published in:

International Journal of Green Energy

Link to article, DOI:

$10.1080 / 15435075.2017 .1382362$

Publication date:

2017

Document Version

Peer reviewed version

Link back to DTU Orbit

Citation (APA):

Zhao, C., Zheng, S., Zhang, J., \& Zhang, Y. (2017). Exergy and economic analysis of organic rankine cycle hybrid system utilizing biogas and solar energy in rural area of China. International Journal of Green Energy, 14(14), 1221-1229. https://doi.org/10.1080/15435075.2017.1382362

\section{General rights}

Copyright and moral rights for the publications made accessible in the public portal are retained by the authors and/or other copyright owners and it is a condition of accessing publications that users recognise and abide by the legal requirements associated with these rights.

- Users may download and print one copy of any publication from the public portal for the purpose of private study or research.

- You may not further distribute the material or use it for any profit-making activity or commercial gain

- You may freely distribute the URL identifying the publication in the public portal 


\section{Exergy and economic analysis of organic rankine cycle hybrid system utilizing biogas and solar energy in rural area of China}

\section{Chunhua Zhao, Siyu Zheng, Ji Zhang \& Yangjun Zhang}

To cite this article: Chunhua Zhao, Siyu Zheng, Ji Zhang \& Yangjun Zhang (2017): Exergy and economic analysis of organic rankine cycle hybrid system utilizing biogas and solar energy in rural area of China, International Journal of Green Energy, DOI: 10.1080/15435075.2017.1382362

To link to this article: http://dx.doi.org/10.1080/15435075.2017.1382362

Accepted author version posted online: 02

Oct 2017.

Submit your article to this journal $\llbracket$

Џ Article views: 18

View related articles $\longleftarrow$

View Crossmark data ¿ 


\title{
EXERGY AND ECONOMIC ANALYSIS OF ORGANIC RANKINE ( Check HYBRID SYSTEM UTILIZING BIOGAS AND SOLAR ENERGY IN RURAL AREA OF CHINA
}

\author{
Zhao Chunhua ${ }^{1}$, Zheng Siyu ${ }^{1 *}$, Zhang $\mathrm{Ji}^{2}$, Zhang Yangjun ${ }^{3}$ \\ ${ }^{1}$ Hubei Key Laboratory of Hydroelectric Machinery Design and Maintenance, \\ China Three Gorges University, Hubei, China; \\ ${ }^{2}$ Department of Mechanical Engineering, Technical University of Denmark, Nils Koppels Allé, \\ Building 403, 2800 Kongens Lyngby, Denmark; \\ ${ }^{3}$ State Key Laboratory of Automotive Safety and Energy \\ Tsinghua University, Beijing, China
}

\begin{abstract}
Due to the existing huge biogas resource in the rural area of China, biogas is widely used for production and living. Cogeneration system provides an opportunity to realize the balanced utilization of the renewable energy such as biogas and solar energy. This paper presented a numerical investigation of a hybrid energy-driven organic Rankine cycle (ORC) cogeneration system, involving a solar organic Rankine cycle and a biogas boiler. The biogas boiler with a module of solar Parabolic-Trough Collectors (PTC) is employed to provide heat source to the ORC via two distinct intermediate pressurized circuits. The cogeneration supplied the power to the air-condition in summer condition and hot water, which is heated in the condenser, in winter condition. The system performance under the subcritical pressures has been assessed according to the energy-exergy and economic analysis with the organic working fluid R123. The effects of various parameters such as the evaporation and condensation temperatures on system performance were investigated. The net power generation efficiency of the cogeneration system is $11.17 \%$, which is $25.8 \%$ higher than that of the base system at an evaporation temperature $110{ }^{\circ} \mathrm{C}$. The exergy efficiency of organic Rankine cycle (ORC) system increases from $35.2 \%$ to 38.2\%. Moreover, an economic analysis of the system is carried out. The results demonstrate that the profits generated from the reduction of biogas fuel and electricity consumption can lead to a significant saving, resulting in an approximate annual saving from $\$ 1,700$ to $\$ 3,000$. Finally, a case study based on the consideration of typical rural residence was performed, which needs a payback period of 7.8 years under the best case.
\end{abstract}

Keywords: Organic Rankine cycle (ORC), Combined heat and power (CHP), Cogeneration, Biogas, Solar, Economic

\section{Introduction}

The efficient use of renewable sources such as solar, biogas and geothermal heat is a significant trend in the future development of China's energy industry, these renewable sources of low and medium grade heat play a key role in displacing the consumption of fossil fuels (Yan Yunfei et al. 2016; Huang Huilane et al. 2015; Liu Qiang et al. 2016; Markides et al. 2015). The multi-generation system can realize the balanced utilization of system energy through the combination of technology, which is regarded as the developmental direction of clean energy efficient utilization (Fang Sun et al. 2009).

Combined heat and power (CHP), also called cogeneration, has the characteristics of energy cascade utilization and higher energy efficiency. The concept of cogeneration aims to combine electricity production with the simultaneous utilization of recoverable energy from the process in order to meet demands for heating. Additional benefits may be realized by serving low temperature heat demands with the discharged cogenerated heat as in renewable sources (e.g., solar) combined heat and power (CHP) applications, thus significantly increasing the system efficiency (Freeman et al. 2015; Calise et al. 2012; Guarracino et al. 2016; Ramos et al. 2017; Tchanche et al. 2011).

At present, various hybrid routines are available and numerous solar-biomass hybrid utilization systems have been developed. Some researchers proposed and evaluated solar-biomass gasification system for producing the electricity and methanol, and some cogeneration system driven by hybrid energy were 
experimentally studied and thermodynamically evaluated (Bai et al. 2015; Zeng et al. 2015; Liao et al. 2015; Wang et al. 2016). Besides, numerous researchers devoted much efforts on optimization with either thermodynamic performance (thermal efficiency, net electricity output, exergy efficiency) or economic factors (levelized energy cost, heat exchanger area per unit power output, specific investment cost) (Guo et al. 2011; Wang Jiangfeng et al. 2010; Sadeghi et al. 2016; Vetter et al. 2013; Delgado-Torres et al. 2010; Katsanos et al. 2012; Liu Qiang et al. 2014). Meanwhile, some studies also carried on the optimization considering both thermodynamic performance and economic factors simultaneously (Delgado-Torres et al. 2010; Li You-Rong et al. 2014; Li Chun 2015). In Greece, a thermodynamic modeling and economic analysis of a micro-scale multi-generation system utilizing biomass fuel and solar power was carried out (Karellas S. et al.2015). The net electricity efficiency was $2.38 \%$ when the heat source temperature was $90{ }^{\circ} \mathrm{C}$. Al-Sulaiman et al. simulated a trigeneration system coupled to an ORC and an absorption chiller (Al-Sulaiman et al. 2011). The maximum exergetic efficiency of trigeneration was $20 \%$. Farrokhi investigated a biomass fuel driven cogeneration system (Farrokhi M. et al. 2014). The maximum electricity power output of this system was 77.4W, and the net electricity efficiency was $1.66 \%$. In China, Zhao Xudong conducted an investigation into an ORC cogeneration system coupled to a fuel gas boiler and a heat pipe, using HFE-7100 as the working fluid (Zhao Xudong et al. 2009). The power generation efficiency and the total efficiency of the system were $16 \%$ and 59\% respectively. China has also made some achievements in cogeneration field, and the scale of China's CHP system has ranked second in the world (Kang Yanbing et al. 2008; Wang Zhengming 2006; Deng Lisheng et al. 2014). There was also an exergy investigation on a modified system combined heat, electricity and steam (Hu Jiahao et al. 2013). The result indicated that the modified system power generation capacity increased while the unit of energy and economic costs of power generation and heat supply reduced at the same biogas consumption. Rao Wenji combined the liquefied natural gas system with the low temperature solar system (Rao Wenji 2014). Comparisons of the combined system and traditional solar ORC system showed the combined system had higher system efficiency and energy efficiency with less mass flow rate. With in-depth research and application, the low temperature ORC system has become more accessible for a wider range. Therefore, the ORC system is recognized as an effective way to recover the low-grade energy.

Biogas energy is widely distributed and has a huge potential in rural area of China as the biogas cogeneration system has a simple structure (Chen Lihong et al. 2017; Chen Qiu, Liu Tianbiao 2017). However, the system efficiency of micro solar ORC system is greatly affected by the weather. In this paper, a hybrid energy driven ORC system utilizing biogas and solar is proposed, a thermodynamic simulation model is established and economic analysis has been studied.

The study includes three parts. The first part is the system description along with some general assumptions considered for the system thermodynamic simulations. In the second part, the system performance evaluations in terms of some primary operational parameters are examined. The economic evaluation of the system is carried out via a case study incorporating meteorological data and heating requirements of an apartment block in China's rural area. The economic investigation is mainly to estimate the savings of the proposed cogeneration system contrasted to conventional methods.

\section{System Description and Thermodynamic Modeling}

\section{System description}

A simple schematic of the system is demonstrated in Fig.1. The system consists of a biogas boiler system and a simple solar PTC cogeneration, both using the feed water as heat transfer fluid. The biogas boiler heating circuit includes a pump, a boiler and an evaporator. The basic components of ORC system include a pump, an expander, a condenser and an evaporator. The whole system has two independent circuits which have their own heat exchangers, where energy is transferred from the heat source to the working fluid. The pressurized working fluid flows into evaporator and is heated into saturated vapor by the hot water from PTC and biogas boiler. After reaching the maximum evaporation temperature, the saturated vapor will flow into the expander to generate mechanical power. The fluid exiting from the expander will enter the condenser in which cooling water is utilized to condense it. Lastly, the saturated liquid returns back to the reservoir. The cooling water exits from the condenser and the waste heat is used to meet the demand of the residents.

Heat Source and Input 
Heat source of ORC system is composed of solar parabolic trough collector (PTC) and biogas boiler. The evaporators of these two independent circuits are connected in series. The heat input is partly from the solar energy and biogas consumption. The pressurized working fluid flows into the evaporators of each circuit, and then absorbs heat from the hot water. The participation of each energy source to the heat input of ORC system varies, which is determined by the relevant parameters, the heat provided by the PTC depends on the total surface area of solar parabolic collectors, the solar energy potential and the daylight hours as well as the Direct Normal Irradiation (DNI). The heat input via biogas boiler depends on the biogas consumption and the biogas fuel availability.

\section{Parabolic Trough Collector (PTC)}

The type of solar collectors in this study is selected as PTC-1000(Werner Weiss MR 2008). Data regarding the PTC's technical and operational characteristics are summarized in Table 1. The conversion efficiency of solar collectors depends on the parameters such as Direct Normal Irradiation (DNI) and the total surface area of solar collectors. The solar energy conversion's efficiency can be expressed by the equation:

$\eta_{P T C}=\eta_{0}-\alpha_{1 a} \cdot \frac{\Delta \bar{T}}{D N I}-\cdot \alpha_{2 a} \frac{\Delta \bar{T}^{2}}{D N I}$

\section{Biogas Boiler}

The maximum load of the biogas boiler is $60 \mathrm{~kW}$, and the boiler efficiency is assumed equal to $85 \%$. The fuel used is methane while the composition and heat value of the fuel (Francescato V et al. 2008) references Table 1. The feed water is heated to $110^{\circ} \mathrm{C}$ in the boiler circuit, and the sufficient pressure is provided by the pump to ensure the hot water is in a saturated liquid state.

\section{Condenser}

The working fluid exiting from the expander is condensed in the condenser, and the condensation temperature is determined by the heating demand of the residents. During this process, the cooling water absorbs the heat from the working fluid and the waste heat can be used to meet the hot water requirement. Table 2 summarizes some general efficiency and temperature assumptions of the system.

\section{Thermodynamic Modeling}

In this section, the simulation of this system is carried out by the Engineering Equation Solver (EES) and MATLAB, and the thermodynamic properties of working fluid are obtained from the National Institute of Standards and Technology (NIST) database REFPROP 7.0. The thermodynamic simulation model is based on the following assumptions: each component of the system is in a steady-flow state, the working fluid at the outlet of evaporator and condenser is saturated, the potential energy and friction loss as well as heat loss in pipes and components are neglected. Figure 2 presents the thermodynamic points of ORC system.

The power balance equation for the system gives:

$$
P_{e l}=\eta_{m} \eta_{G} P_{E X P}-\frac{P_{P U M P}}{\eta_{M}}
$$

In the above equation, $\eta_{G}$ is the generation efficiency and $\eta_{m}$ is the mechanical efficiency. $P_{e l}, P_{P U M P}$ and $P_{E X P}$ represents the net electricity output, electricity consumption of the pump and the total electricity output, respectively.

The heat output during the condensation process is given by the equation:

$$
\begin{aligned}
& Q_{h}=m_{O R C}\left(h_{4}-h_{1}\right) \\
& =m_{\text {water }} C p_{\text {water }} \Delta T_{\text {water }}
\end{aligned}
$$

In the above equation, $m_{O R C}$ represents the mass flow rate of the working fluid in ORC system and $m_{\text {water }}$ represents the mass flow rate of the cooling water in condenser. $C p_{\text {water }}$ is the specific heat capacity of water, $\Delta T_{\text {water }}$ represents the cooling water's temperature difference. $h_{1}$ is the specific enthalpy of working fluid at the condenser outlet, and $h_{4}$ is the specific enthalpy of the working fluid at the evaporator outlet in solar collection circuit. 
The total heat input to the working fluid in the ORC is equal to:

$$
Q_{b i o}+Q_{P T C}=m_{O R C}\left(h_{3}-h_{2}\right)
$$

In the above equation, $Q_{P T C}$ and $Q_{b i o}$ represents the heat provided to the ORC system through the PTC and the biogas boiler. $h_{2}$ is the specific enthalpy of the working fluid at the pump outlet, and $h_{3}$ is the specific enthalpy of the working fluid at the evaporator outlet in the biogas boiler heating circuit.

And,

$$
\begin{aligned}
& Q_{\text {bio }}=\eta_{b} v_{\text {bio }} H H V_{\text {bio }} \\
& =m_{\text {water,bio }} C p_{\text {water }} \Delta T_{\text {water,bio }} \\
& Q_{P T C}=\eta_{P T C} D N I \cos \theta A_{P T C} \\
& =m_{\text {water }, P T C} C p_{\text {water }} \Delta T_{\text {water }, P T C}
\end{aligned}
$$

In the above equation, $\eta_{b}$ and $\eta_{P T C}$ represent the boiler efficiency and PTC efficiency, $v_{b i o}$ and $H H V_{b i o}$ are the volume flow rate and high heating value of biogas, DNI is the Direct Normal Irradiation and $A_{P T C}$ is the total surface area of the PTC. $m_{\text {water,bio }}$ and $m_{\text {water,PTC }}$ are the mass flow rate of the feed water in biogas boiler heating circuit and solar collection circuit. $\Delta T_{\text {water,bio }}$ and $\Delta T_{\text {water,PTC }}$ are the temperature variation in each circuit.

The performance of the system is evaluated by employing a set of indicators which are:

ORC thermal efficiency:

$$
\eta_{t h}=\frac{\left(h_{3}-h_{4}\right)-\left(h_{2}-h_{1}\right)}{h_{3}-h_{1}}
$$

System electric efficiency:

$$
\eta_{e l}=\frac{P_{e l}}{m_{N F B} H H V_{N F B}+D N I \cdot \cos \theta A_{P T C}}
$$

Where $\eta_{t h}$ and $\eta_{e l}$ are the ORC thermal efficiency and the system electric efficiency.

The exergy balance of the system is calculated as:

$$
E x_{\text {in }}-E x_{\text {out }}=P_{\text {el }}+E x_{\text {heat }}+I \quad(8
$$

Where $E x_{\text {in }}$ and $E x_{\text {out }}$ represent the input and output exergy of the system. Ex heat is the exergy of total heat generated by the system and I is the total system irreversibility.

The overall exergy efficiency $\eta_{e x}$ is defined as:

$$
\eta_{\text {ex }}=\frac{P_{e l}+E x_{\text {heat }}}{E x_{\text {in }}}
$$

Depending on the definition of the system boundaries, the inlet exergy can refer to either the exergy of hot water stream flowing through the evaporator or the exergy of the biogas and the solar radiation absorbed by the PTC. Therefore, in order to simplify the calculation, the overall inlet exergy is calculated by the sum of the exergy of the hot water stream entering each evaporator.

The exergy of each fluid stream is given by the equation:

$$
E x=h-h_{0}-T_{0}\left(s-s_{0}\right) \quad(10)
$$

In the above equation, $T_{0}$ and $s_{0}$ refer to the condition of $101.3 \mathrm{kPa}$ and $25^{\circ} \mathrm{C} . E, h$ and $s$ are the specific exergy, enthalpy and entropy of each point in cycle.

\section{Thermodynamic Analysis}

The effect of the evaporation temperature and working fluid selection

According to the selection principle of the working fluid (Wang Huitao, Wang Hua 2009; Han Zhonghe et al. 2012; Wang Dongxiang et al. 2013; Feng Yongqiang et al. 2015), R236fa, R123, R245fa and RC318 are selected as candidates. The performance of the working fluid is evaluated by employing thermal and exergy efficiency of the system. It is assumed that the condensation temperature of the working fluid takes place around $30{ }^{\circ} \mathrm{C}$, the range of evaporation temperature is between $65{ }^{\circ} \mathrm{C}$ and $90{ }^{\circ} \mathrm{C}$, and $T_{e v}$ presents the evaporation temperature of the working fluid. The effect of the four candidates on the system's performance at different temperatures is shown in Figure 3. Fig.3 presents that the thermal and exergy efficiency increase with the increasing evaporation temperature. R123 exhibits the highest thermal efficiency as well as exergy 
efficiency among R123, R236fa, R245fa and RC318. Furthermore, since it is a dry fluid, it does not require superheating. Consequently, R123 is selected as working fluid for the present work.

\section{The effect of the condensation temperature}

It is assumed that the evaporation temperature is around $90^{\circ} \mathrm{C}$ and the condensation temperature ranges from $30^{\circ} \mathrm{C}$ to $60^{\circ} \mathrm{C}$. Figure 4 shows the effect of condensation temperature on the heating and power generation. As condensation temperature increases, the thermal and the exergy efficiency of the system decrease. Moreover, when the pinch point temperature of the condenser is fixed, the cooling water outlet temperature increases progressively with the condensation temperature increases. For the sufficient production of space heating and hot water, the condensation temperature should not be lower than $40^{\circ} \mathrm{C}$. Consequently, a proper condensation temperature should be around $50{ }^{\circ} \mathrm{C}$. Moreover, reducing the temperature of cooling water can increase the system power generation capacity, and this temperature directly affects the demand of electricity generation and heating supply.

\section{Exergy Analysis}

The irreversibility, which is carried out by exergy analysis, directly reflects exergy losses caused by irreversible factors in each component (Sun Faming et al. 2012; Lecompte et al. 2014; Gao P. et al. 2015; Ahmadi et al. 2012). The exergy efficiency not only emphasizes the importance of the net power that is produced over the thermal conversion efficiency, but also indicates the extent of effective energy utilization. The exergy analysis of each components is carried out as shown in Section 2.4. It is assumed that the system operation is under the steady state; the working fluid enters the expander and exits the condenser with a saturated state; and the heat loss to environment could be negligible.

The present work conducts exergy analysis under two different operation modes. In mode A, only biogas boiler supplies the heat to the working fluid. The nominal load of the biomass boiler for the application is 60 $\mathrm{kWth}$, while the boiler efficiency is defined as $85 \%$. The feed water in the biogas boiler circuit is heated to $110{ }^{\circ} \mathrm{C}$, and the temperature of saturated vapor at expander inlet is $90^{\circ} \mathrm{C}$. In mode $\mathrm{B}$, both the biogas boiler system and the solar PTC system are used as the heat source to supply energy to the ORC system. According to the solar energy resource data of Hubei Province (Liu Kequn et al. 2007), and the investigation about the performance of parabolic trough collector (Bouvier et al. 2015), the total surface area of PTC is assumed equal to $70 \mathrm{~m}^{2}$. Due to the additional contribution of the solar PTC system to the heat input, the temperature of feed water in solar energy collection circuit can be heated up to $139{ }^{\circ} \mathrm{C}$, under the ideal condition and the evaporation temperature can be raised up to $110^{\circ} \mathrm{C}$. In both of the two operation modes, the mass flow rate of the working fluid is assumed equal to $1.0 \mathrm{~kg} \cdot \mathrm{s}^{-1}$ and the cooling water outlet temperature is fixed as $40{ }^{\circ} \mathrm{C}$.

As demonstrated in Table 3, in either mode A or mode B, half of the total irreversibility occurs in the evaporator, it is close to $18 \%$ of total exergy input. The reason is that there is a higher temperature difference between the hot feed water in the evaporator and the working fluid of the ORC system, and a large amount of heat input is not utilized in the process of heat exchange. Secondly, the irreversibility takes place in the condenser is approximate to $16 \%$, which is essential in order to supply sufficient heat to the cooling water for meeting the heating demand. The third significant components of the irreversibility occur during the expansion of the working fluid in the expander, due to the lower exergy efficiency of the expander $(70 \%-75 \%)$.

As exhibited in Table 3, in Mode B, the evaporation temperature increases due to the solar collectors supply the additional contribution to the heat input, so that the total amount of power generation of Mode B is nearly three times over the Mode A, and the exergy efficiency is also increased obviously. Consequently, the performance of cogeneration system utilizing biogas and solar energy is substantially increased compared to the single heat source supply mode. 


\section{Economic evaluation}

A higher net specific work and cooling water temperature can be achieved by improving the heat source temperature. Due to the limited increasing system cost by heating the working fluid, expanding the area of the PTC and installing the extra heat exchangers is undesirable. On this principle, the system structure should keep simpler and lower cost of the PTC area as well as additional heat exchangers (superheater and regenerator). Consequently, the operation condition of the system is fixed as demonstrated in Table 4.

The economic evaluation of the proposed system is conducted with the purpose to estimate the annual savings generated from the production of heat, electricity and subsequently calculate the cost efficiency of the system (Fredy et al. 2012; Feng Yongqiang et al. 2015; Toffolo et al. 2014). The evaluation criteria used are standard coal saving per year and the payback period(PBP) of the whole system.

Standard coal savings

It is assumed that the system is installed in a typical residence in rural area of southern China, and the economic evaluation is carried out under two seasons. The operation mode can alternate between summer and winter. During the summer, there is no demand of space heating, and the system just need to supply domestic heating water and electricity. In this manner, the cooling water outlet temperature is set as $40^{\circ} \mathrm{C}$, and the power produced by the system is adequate for the residence power supply in order for the system to be independent from external power sources. While in winter, the major demand of the residents is domestic hot water and space heating. Therefore, the condensation temperature is set at $50^{\circ} \mathrm{C}$, due to the fixed pinch point temperature, the cooling water outlet temperature is about $45^{\circ} \mathrm{C}$, the electricity output could be used to satisfy the power consumption of the system. Although there are possible benefits of the system in regards to the heat generation capacity, the present work intends to demonstrate the potential of power production of the ORC-CHP.

According to the residential design standards of China (Qin Yi 2014; Xu Xiaogang 2008), it is assumed that daily hot water consumption of each resident is equal to around $60 \mathrm{~L}$ at $50{ }^{\circ} \mathrm{C}$, and the water used for heating should be at $45^{\circ} \mathrm{C}$ In order to estimate the average monthly electricity and heat generation, the assumption of monthly operation period is respectively set as 200 hours in summer and 120 hours in winter. Moreover, the PTC provides a varying amount of energy input to the system, depending on the DNI and operation period of each month, the biogas boiler provides the additional heat required, based on the assumptions described above. The evaluation of the power and the heat generation of the system under two seasons is summarized in Table 5.

As shown in Table 5, the power and the heat generation produced by the system are approximate $1042 \mathrm{~kW}$. $\mathrm{h}$ and $7300 \mathrm{~kW} \cdot \mathrm{h}$ per month during the ideal winter operation condition. In the summer mode, the amount of monthly power and heating generation are almost $3144 \mathrm{~kW} \cdot \mathrm{h}$ and $17500 \mathrm{~kW} \cdot \mathrm{h}$. Consequently, the total annual electricity and heating generation are $25116 \mathrm{~kW} \cdot \mathrm{h}$ and $148806 \mathrm{~kW} \cdot \mathrm{h}$ respectively. Since the average standard coal consumption of power generation is $320 \mathrm{~g} \cdot \mathrm{kW}^{-1} \cdot \mathrm{h}^{-1}$, the total amount of the system power and heat generation is equal to the energy produced by 57.97 tons of standard coal consumption (Tu Hua et al. 2014; Ahmadi et al. 2011).

\section{Payback period (PBP)}

This section of present work just evaluates the main components' investment of the whole system including solar collectors, ORC system and biogas boiler heating system. The total capital investment is assessed by the module cost calculation.

PTC and ORC modules have been commercialized and several corresponding investigations about the costs of PTC and ORC modules have been done (Sotirios et al. 2016; Qiu G et al. 2011). The current investment costs for micro scale ORCs are substantially increased (Qiu G et al. 2011; Algieri et al. 2013) compared to larger systems. The results further showed that ORC modules costs ranges from $\$ 7,000$ to $\$ 11,000$. Moreover, due to the uncertainty of the market prices of micro scale ORC modules and PTC, the solar ORC system economic analysis will be carried out with the values from $\$ 15,000$ to 19,000 (Sotirios et al. 2016).

The investment cost of biogas boiler heating system varies greatly depends on the size of the system (Sotirios et al. 2016), and some investigations show that the capital investment for domestic size boilers varies from $\$ 300$ to $\$ 700$. 
Payback period (PBP) is commonly used for evaluating the performance of different programs in economic. For the $P B P$, it is described by the equation:

$$
P B P=C_{n} / S_{n}
$$

Where $S_{n}$ represents the net savings per year $n ; C_{n}$ and $k$ are the total investment and interest rate.

$$
C_{n}=C_{0} \cdot\left(1+\eta_{1}+\eta_{2}+\eta_{3}\right)^{n}
$$

Where $C_{0}$ is the initial investment; $\eta_{1}, \eta_{2}$ and $\eta_{3}$ represent the rates of maintenance cost and supplies as well as the cost of management and security of the whole system, respectively; the value of each rate is accounted for $2 \%, 0.3 \%$ and $0.7 \%$. The operation period of the system is assumed as 20 years and an interest rate is equal to $5 \%$.

The parameters in the Eq. (11-12) have been employed in several studies (Yagoub W. et al. 2006; Fredy et al. 2012; Feng Yongqiang et al. 2015; Toffolo et al. 2014), and the total system capital investments calculated by the equations range from $\$ 17,000$ to $\$ 23,000$. As calculated in Section 4.1, the electricity and the heating generated by the ORC-CHP system are $25116 \mathrm{~kW} \cdot \mathrm{h}$ and $148806 \mathrm{~kW} \cdot \mathrm{h}$ respectively, which are equal to the energy produced by standard coal consumption of 57.97 tons. Depending on the rang of the standard coal price (49 85 \$/t), the annual saving is approximately $\$ 1,700 \sim 3,000$, which need the payback period of 7.8 years and 13.5 years under the best and worst cases respectively.

\section{Conclusions}

An ORC-CHP cogeneration system based on the utilization of biogas and solar energy was thermodynamically and economically investigated. For the range of operation temperatures examined, it was determined that the thermal efficiency of the ORC system is maximized when R123 was selected as the working fluid at an evaporation temperature of $110^{\circ} \mathrm{C}$. In the optimal situation, the net power output is equal to $14.31 \mathrm{~kW}$, and the net power generation efficiency of the cogeneration system is $11.2 \%$, which is $25.8 \%$ higher than that of the base system. The exergy efficiency of the ORC system increases from $35.2 \%$ to $38.2 \%$. The thermal and exergy efficiency of the cogeneration system are substantially increased compared to the single heat source supply mode. The numerical results indicated that the superheating by adding a recuperator does not lead to a significant increase of the system efficiency; instead, it results in much larger heat exchanger and therefore requiring more solar collectors' area.

An economic assessment of the cogeneration system was carried out for a case study of the typical residence in the rural area of southern China. An economic analysis of the PBP was performed in order to distinguish their impact on the system cost effectiveness. It was demonstrated that the profits generated from the reduction of biogas fuel and electricity consumption can lead to significant savings, accounting for annual saving of the system is approximately from $\$ 1,700$ to $\$ 3,000$ and a payback period of 7.8 years (best case). However, as the primary components of the system have not yet been commercially available on a large scale in China, the investment of these equipment remains high. For all that, even for the worst case (high total investment case), the ORC-CHP system proposed still exhibits positive economic results.

\section{Acknowledgment}

The authors acknowledge the support provided by the State Key Laboratory of Automotive Safety and Energy of Tsinghua University the CERNET Innovation Project(NG II20150801) and the Natural Science Foundation of China (NSFC) for financing support (project number 51375048). Most of the thermodynamic simulation and calculation of the present work is done with their assistance. This cogeneration system is currently under construction in the Laboratory of Hydroelectric Machinery Design and Maintenance of the China Three Gorges University. 


\section{References}

Al-Sulaiman F.A., F. Hamdullahpur and I. Dincer. 2011. Greenhouse gas emission and exergy assessments of an integrated organic Rankine cycle with a biomass combustor for combined cooling, heating and power production. Applied Thermal Engineering 31: 439-446.

Ahmadi, P., M.A. Rosen and I. Dincer. 2012. Multi-objective exergy-based optimization of a polygeneration energy system using an evolutionary algorithm. Energy 46:21-31.

Algieri A, Morrone P. 2013. Energetic analysis of biomass-fired ORC systems for micro-scale combined heat and power (heat pump) generation. Applied Thermal Engineering 71:751-759.

Ahmadi, P., M.A. Rosen and I. Dincer. 2011. Greenhouse gas emission and exergo-environmental analyses of a trigeneration energy system. International Journal of Greenhouse Gas Control 5:1540-1549.

Bouvier J., Michaux G., Salagnac P., et al. 2015. Experimental characterisation of a solar parabolic trough collector used in a micro-CHP (micro-cogeneration) system with direct steam generation. Energy 83: 474-485.

Bai Z, Liu Q, Lei J, Li H, Jin H. 2015. A polygeneration system for the methanol production and the power generation with the solar-biomass thermal gasification. Energy Conversion \& Management 102:190-201.

Chen Lihong, Rong-Gang Cong, Bangrong Shu, et al. 2017. A sustainable biogas model in China: The case study of Beijing Deqingyuan biogas project. Renewable and Sustainable Energy Review 78:773-779.

Chen Qiu, Tianbiao Liu. 2017. Biogas system in rural China: Upgrading from decentralized to centralized? Renewable and Sustainable Energy Review 78:933-944.

Calise F., d'Accadia MD, Vanoli L. 2012. Design and dynamic simulation of a novel solar trigeneration system based on hybrid photovoltaic/thermal collectors (PVT). Energy Conversion \& Management 60:214-25.

Delgado-Torres, A.M. and L. García-Rodríguez. 2010. Analysis and optimization of the low-temperature solar organic Rankine cycle (ORC). Energy Conversion and Management 51:2846-2856.

Deng Lisheng, Huang Hongyu, He Zhaohong, et al. 2014. Research Progress on Organic Rankine Cycle. Advances in New and Renewable Energy 2:180-189.

Fang Sun, Yang Zhao, Chen Yiguang. 2009. The Exergy loss analysis of the combined cooling heating and cooling system for gas turbine. Journal of Engineering for Thermal Energy and Power 24:53-59.

Feng Yongqiang, T.C. Hung, K. Greg, et al. 2015. Thermoeconomic comparison between pure and mixture working fluids of organic Rankine cycles (ORCs) for low temperature waste heat recovery. Energy Conversion and Management 106:859-872.

Farrokhi M., S.H. Noie and A.A. Akbarzadeh. 2014. Preliminary experimental investigation of a natural gas-fired ORC-based micro-CHP system for residential buildings. Applied Thermal Engineering 69:221-229.

Fredy Vélez, J.J. Segovia , M.C. Martín, et al. 2012. A technical. economical and market review of organic Rankine cycles for the conversion of low-grade heat for power generation. Renewable and Sustainable Energy Reviews 16:4175-4189.

Francescato V, Antonini E, Bergomi L. 2008. Wood fuels handbook, production, quality requirements, trading. AIEL-Italian Energy Association.

Feng Yongqiang, Y. Zhang, B. Li, et al. 2015. Sensitivity analysis and thermoeconomic comparison of ORCs (organic Rankine cycles) for low temperature waste heat recovery. Energy 82:664-677.

Freeman J., Hellgardt K., Markides CN. 2015. An assessment of solar-powered organic Rankine cycle systems for combined heating and power in UK domestic applications. Applied Energy 138:605 - 620.

Freeman J., Hellgardt K., Markides CN. 2017. Working fluid selection and electrical performance optimisation of a domestic solar-ORC combined heat and power system for year-round operation in the UK. Applied Energy 186:291 - 303.

Guo T., H.X. Wang and S.J. Zhang. 2011. Fluids and parameters optimization for a novel cogeneration system driven by low-temperature geothermal sources. Energy 36:2639-2649.

Guo T., H.X. Wang and S.J. Zhang. 2011. Fluids and parameters optimization for a novel cogeneration system driven by low-temperature geothermal sources. Energy 36:2639-2649.

Gao, P., L. Jiang, L.W. Wang, R.Z. Wang, F.P. Song, et al. 2015. Simulation and experiments on an ORC system with different scroll expanders based on energy and exergy analysis. Applied Thermal Engineering 75: 880-888.

Guarracino I, Mellor A., Ekins-Daukes NJ, Markides CN. 2016. Dynamic coupled thermal-and-electrical modelling of sheet-and-tube hybrid photovoltaic/thermal (PVT) collectors. Applied Thermal Engineering 101:778-95.

Huang Huilan, Chen Qiang, Li Gang. 2015. Research progress in low grade energy generation systems. Thermal Power Generation 08: 8-13.

$\mathrm{Hu}$ Jiahao, Luo Xianglong, Chen Ying, et al. 2103. Reconstruction and exergy economic analysis of natural gas cogeneration system. Journal of Engineering for Thermal Energy and Power 28:573-579.

Han Zhonghe, Ye Yilin, Liu Yun. 2012. Effect of working fluids on performance of solar Organic Rankine Cycles. Journal of Chinese Society of Power Engineering 32:229-234.

Katsanos, C.O., D.T. Hountalas and E.G. Pariotis. 2012. Thermodynamic analysis of a Rankine cycle applied on a diesel truck engine using steam and organic medium. Energy Conversion and Management 60:68-76.

Karellas Sotirios, K. Braimakis. 2016. Energy-exergy analysis and economic investigation of a cogeneration and trigeneration ORC-VCC hybrid system utilizing biomass fuel and solar power. Energy Conversion \& Management 107:103-113.

Kang Yanbing, Zhang Jianguo, Zhang Yang. 2008. Development status, problems and suggestions of central heating in China. Energy of China 30: 8-13.

Lecompte, S., B. Ameel, D. Ziviani, MVD Broek, et al. 2014. Exergy analysis of zeotropic mixtures as working fluids in Organic 
Rankine Cycles. Energy Conversion and Management 85:727-739.

Liu Qiang, Linlin Shang, Yuanyuan Duan. 2016. Performance analyses of a hybrid geothermal - fossil power generation system using low-enthalpy geothermal resources. Applied Energy 162:149-162.

Liu Qiang, Yuanyuan Duan, Zhen Yang. 2014. Effect of condensation temperature glide on the performance of organic Rankine cycles with zeotropic mixture working fluids. Applied Energy 115: 394-404.

Liu Kequn, Chen Zhenghong, Xia Zhihong. 2007. Spatial and Temporal Distribution Characteristics and Regionalization of Solar Energy Resources in Hubei Province. Journal of Huazhong Agricultural University 26: 888-893.

Li You-Rong, M.T. Du, C.T. Wu, et al. 2014. Economical evaluation and optimization of subcritical organic Rankine cycle based on temperature matching analysis. Energy 68: 238-247.

Li Chun. 2015. Comparative study on the thermo-economic performance of ORC under different heat source conditions and utilizing patterns. Chongqing University

Liao B, Guo LJ, Lu YJ, Zhang XM. 2013. Solar receiver/reactor for hydrogen production with biomass gasification in supercritical water. International Journal of Hydrogen Energy 38:13038-44.

Markides CN. 2015. Low-concentration solar-power systems based on organic Rankine cycles for distributed-scale applications: overview and further developments. Frontiers Energy Research 3:47.

Qin Yi. 2014. The research on household energy consumption in China, Shanxi University of Finance \& Economics.

Qiu G., Liu H, Riffat S. 2011. Expanders for micro-CHP systems with organic Rankine cycle. Applied Thermal Engineering 31:3301-3307.

Ramos A., Chatzopoulou MA, Guarracino I., Freeman J., Markides CN. 2017. Hybrid photovoltaic-thermal solar systems for combined heating, cooling and power provision in the urban environment. Energy Conversion \& Management http://dx.doi.org/10.1016/j.enconman.

Rao Wenji. 2014. Research of the Combined Cycle Utilizing Cold Energy of LNG and Low-temperature Solar Energy. Chongqing University.

Ravaghi-Ardebili Z, Manenti F, Corbetta M, Pirola C, Ranzi E. 2015. Biomass gasification using low-temperature solar-driven steam supply. Renewable Energy 74:671-80.

Sadeghi Mohsen, A. Nemati, A. Ghavimi, et al. 2016. Thermodynamic analysis and multi-objective optimization of various ORC (organic Rankine cycle) configurations using zeotropic mixtures. Energy 109: 791-802.

Sun Faming, Y. Ikegami, B. Jia ,et al. 2012. Optimization design and exergy analysis of organic rankine cycle in ocean thermal energy conversion. Applied Ocean Research 35:38-46.

Sotirios Karellas, Konstantinos Braimakis. 2016. Energy-exergy analysis and economic investigation of a cogeneration and trigeneration ORC-VCC hybrid system utilizing biomass fuel and solar power. Energy Conversion and Management 107:103-113.

Toffolo Andrea, A. Lazzaretto, G. Manente ,et al. 2014. A multi-criteria approach for the optimal selection of working fluid and design parameters in Organic Rankine Cycle systems. Applied Energy 121:219-232.

Tu Hua, Liu Cuijie. 2014. Calculation of $\mathrm{CO}_{2}$ emission of standard coal. Coal Quality Technology 2:57-60.

Tchanche BF, Lambrinos G, Frangoudakis A, Papadakis G. 2011. Low-grade heat conversion into power using organic Rankine cycles - a review of various applications. Renewable \& Sustainable Energy Reviews 15:3963-3979.

Vetter Christian, H. Wiemer and D. Kuhn. 2013. Comparison of sub- and supercritical Organic Rankine Cycles for power generation from low-temperature/low-enthalpy geothermal wells, considering specific net power output and efficiency. Applied Thermal Engineering 51:871-879.

Wang Jiangfeng, Zhixin Sun, Yiping Dai, et al. 2010. Parametric optimization design for supercritical CO2 power cycle using genetic algorithm and artificial neural network. Applied Energy 87:1317-1324.

Wang Zhenming. 2006. New Development of China cogeneration and distributed energy. Journal of Shenyang Institute of Engineering (Natural Science) 2:1-5.

Wang Huitao, Wang Hua. 2009. Selection of working fluid for low-temperature solar thermal power generation organic Rankine cycles, Journal of Power Engineering 29:287-291.

Wang Dongxiang, Ling Xiang, Peng Hao. Investigation on working fluid selection of organic Rankine cycle for low temperture waste heat, http://www.paper.edu.cn/releasepaper/content/201311-75.

Wang JJ, Yang Y. 2016. Energy, exergy and environmental analysis of a hybrid combined cooling heating and power system utilizing biomass and solar energy. Energy Conversion \& Management 124:556-77.

Werner Weiss MR. 2008. Process heat collectors: state of the Art Within Task 33/IV. Gleisdorf, Feldgasse 19, Austria: AEE-Institute for Sustainable Technologies, Fraunhofer Institute for Solar Energy Systems.

$\mathrm{Xu}$ Xiaogang. 2008. Analysis of China's rural life energy comsuption, Chinese Academy of Agricultural Sciences.

Yan Yunfei, Zhang Zhi'en, Zhang Li, et al. 2012. Solar energy utilization technology and Application. Acta Energiae Solaris Sinica s1: 47-56.

Yagoub W., P. Doherty, S.B. Riffat. 2006. Solar energy-gas driven micro-CHP system for an office building. Applied Thermal Engineering 26:1604-1610.

Zhao Xudong, Shuang Yang, Zhiyin Duan, Saffa B. Riffat. 2009. Feasibility study of a novel dew point air conditioning system for China building application. Building and Environment 44:1990-1999.

Zeng K, Gauthier D, Lu J, Flamant G. 2015. Parametric study and process optimization for solar pyrolysis of beech wood. Energy Conversion \& Management 106:987-98. 
Tab. 1 Boiler and PTC technical and operational characteristics

\begin{tabular}{l|l}
\hline \multicolumn{1}{c|}{ Biogas Boiler } & \multicolumn{1}{|c}{$\begin{array}{c}\text { Parabolic Trough } \\
\text { Collector }(\text { PTC })\end{array}$} \\
\hline Maximum load: 60kW & Type: PTC-1000 \\
Maximum water & Operation temperature: \\
temperature: $110{ }^{\circ} \mathrm{C}$ & $80 \sim 300^{\circ} \mathrm{C}$ \\
High heat value of fuel & Heat transfer medium: \\
Gas (HHV): $17 \mathrm{MJ} \cdot \mathrm{m}^{-3}$ & water \\
Boiler efficiency: 85\% & $\begin{array}{l}\text { Efficiency parameters: } \\
\eta_{0}=0.75 \\
\end{array}$ \\
& $\alpha_{1 a}=0.1123 \mathrm{~W} \cdot\left(\mathrm{m}^{2} \cdot \mathrm{K}\right)^{-1}$ \\
& $\alpha_{2 a}=0.00128 \mathrm{~W} \cdot\left(\mathrm{m}^{2} \cdot \mathrm{K}^{2}\right)^{-1}$ \\
& \\
\hline
\end{tabular}


Tab. 2 Efficiency and temperature assumptions of the system

\begin{tabular}{l|l|l}
\hline ORC & Biogas boiler circuit & PTC circuit \\
\hline Pump isentropic efficiency: 70\% & $\begin{array}{l}\text { Temperature difference at hot } \\
\text { and cold sides of heat } \\
\text { exchangers: 8K }\end{array}$ & $\begin{array}{l}\text { Temperature difference at hot } \\
\text { and cold sides of heat } \\
\text { exchangers: 10K }\end{array}$ \\
Expander isentropic efficiency: 75\% & $\begin{array}{l}\text { Pinch point of the evaporation: } \\
8 \mathrm{~K}\end{array}$ & $\begin{array}{l}\text { Pinch point of the evaporation: } \\
8 \mathrm{~K}\end{array}$ \\
Generator efficiency: 98\% &
\end{tabular}


Tab. 3 Exergy analysis of the system for Modes A and B

Evaporation temperature $T_{e v}=90^{\circ} \mathrm{C}$

Mass flow rate of the working fluid

$$
m=0.3 \mathrm{~kg} \cdot \mathrm{s}^{-1}
$$

Mass flow rate of the cooling water

\begin{tabular}{c} 
Components/Syst \\
em \\
\hline Evaporator \\
Expander \\
Condenser \\
Pump \\
ORC system \\
Net electricity \\
output \\
The exergy of hot \\
water \\
Total exergy \\
output
\end{tabular}

Total exergy input

Electricity efficiency

\section{MODE A}

\section{MODE B}

Evaporation temperature $T_{e v}=110^{\circ} \mathrm{C}$

Mass flow rate of the working fluid

$$
m=0.6 \mathrm{~kg} \cdot \mathrm{s}^{-1}
$$

Mass flow rate of the cooling water $m=1.3 \mathrm{~kg} \cdot \mathrm{s}^{-1}$ $m=0.6 \mathrm{~kg} \cdot \mathrm{s}^{-1}$

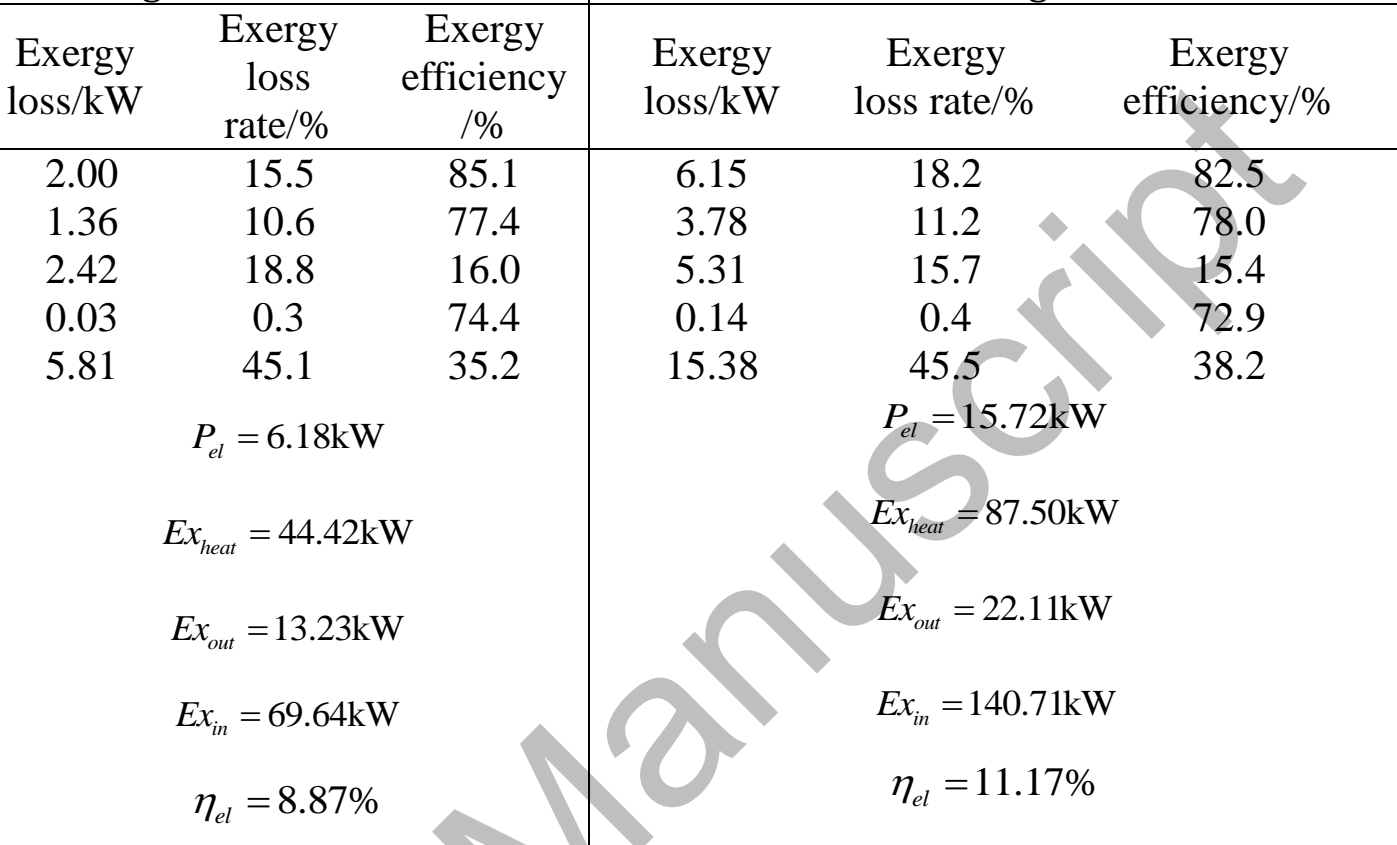


Tab. 4 ORC thermodynamic points and system performance parameters

\begin{tabular}{|c|c|c|c|c|c|}
\hline Points & $T /{ }^{\circ} \mathrm{C}$ & $p / \mathrm{kPa}$ & $h / \mathrm{kJ} \cdot \mathrm{kg}^{-1}$ & $s / \mathrm{kJ} \cdot \mathrm{kg}^{-1} \cdot \mathrm{K}^{-1}$ & Operation parameters \\
\hline 1 & 45.0 & 181.68 & 245.81 & 1.15 & $\begin{array}{c}\text { Environment } \\
\text { temperature : } 20^{\circ} \mathrm{C}\end{array}$ \\
\hline 2 & 45.6 & 976.03 & 246.61 & 1.16 & $\begin{array}{l}\text { Mass flow rate of working } \\
\text { fluid: } 0.69 \mathrm{~kg} \cdot \mathrm{s}^{-1}\end{array}$ \\
\hline 3 & 110.0 & 976.03 & 444.88 & 1.69 & $\begin{array}{l}\text { Mass flow rate of cooling } \\
\text { water: } 1.3 \mathrm{~kg} \cdot \mathrm{s}^{-1}\end{array}$ \\
\hline 4 & 65.0 & 181.68 & 423.42 & 1.71 & $\begin{array}{l}\text { Mass flow rate of heat source: } \\
\qquad 1.0 \mathrm{~kg} \cdot \mathrm{s}^{-1}\end{array}$ \\
\hline $\begin{array}{l}\text { A (heat source } \\
\text { inlet) }\end{array}$ & 139.0 & 350.93 & 584.66 & 1.73 & \\
\hline $\begin{array}{l}\text { B (heat source } \\
\text { outlet) }\end{array}$ & 110.0 & 144.59 & 462.47 & 1.42 & $4.31 \mathrm{~kW}$ \\
\hline $\begin{array}{c}\mathrm{C} \text { (cooling } \\
\text { water inlet) }\end{array}$ & 20 & 2.33 & 83.71 & & $E x_{\text {heat }}=85.96 \mathrm{~kW}$ \\
\hline $\begin{array}{c}\mathrm{D} \text { (cooling } \\
\text { water outlet) }\end{array}$ & 40.0 & 7.52 & 169.00 & & \\
\hline
\end{tabular}


Tab. 5 The evaluation of the power and heat generation of the system for summer and winter

\begin{tabular}{ccc}
\hline & Winter & Summer \\
\hline Operation period & October-March & April-September \\
Environment temperature & $10^{\circ} \mathrm{C}$ & $20^{\circ} \mathrm{C}$ \\
Evaporation temperature & $98^{\circ} \mathrm{C}$ & $110^{\circ} \mathrm{C}$ \\
Heating water temperature & $45^{\circ} \mathrm{C}$ & $40^{\circ} \mathrm{C}$ \\
Power generation per month & $1042 \mathrm{kWe} \cdot \mathrm{h}$ & $3144 \mathrm{kWe} \cdot \mathrm{h}$ \\
Heat generation per month & $7300 \mathrm{kWth} \cdot \mathrm{h}$ & $17500 \mathrm{kWth} \cdot \mathrm{h}$ \\
\hline
\end{tabular}


Fig. 1 The combined ORC and biogas boiler and PTC heating water circuits

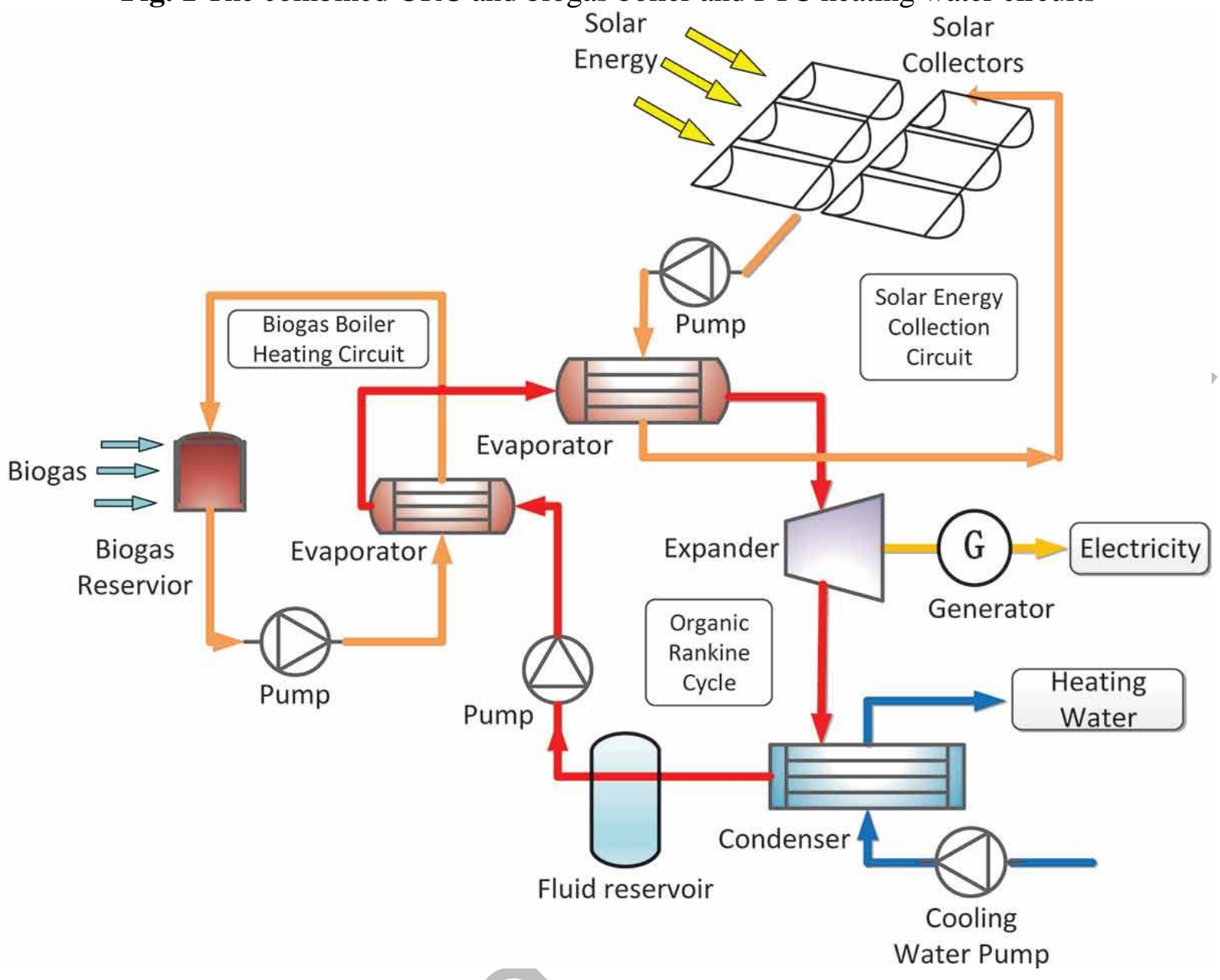


Fig. 2 The thermodynamic points of ORC

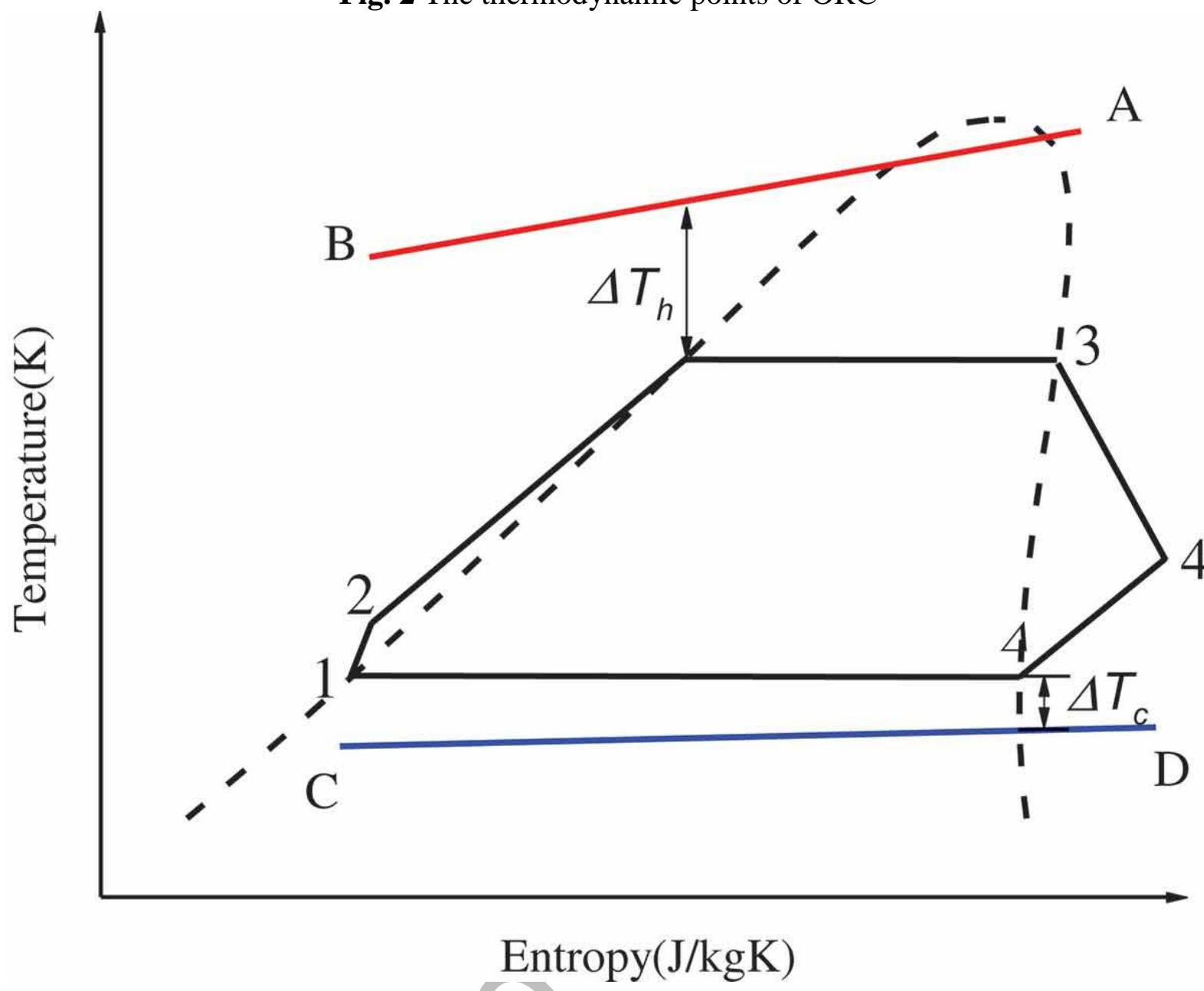


Fig. 3 Effect of the evaporation temperature of the system on thermal and exergy efficiency

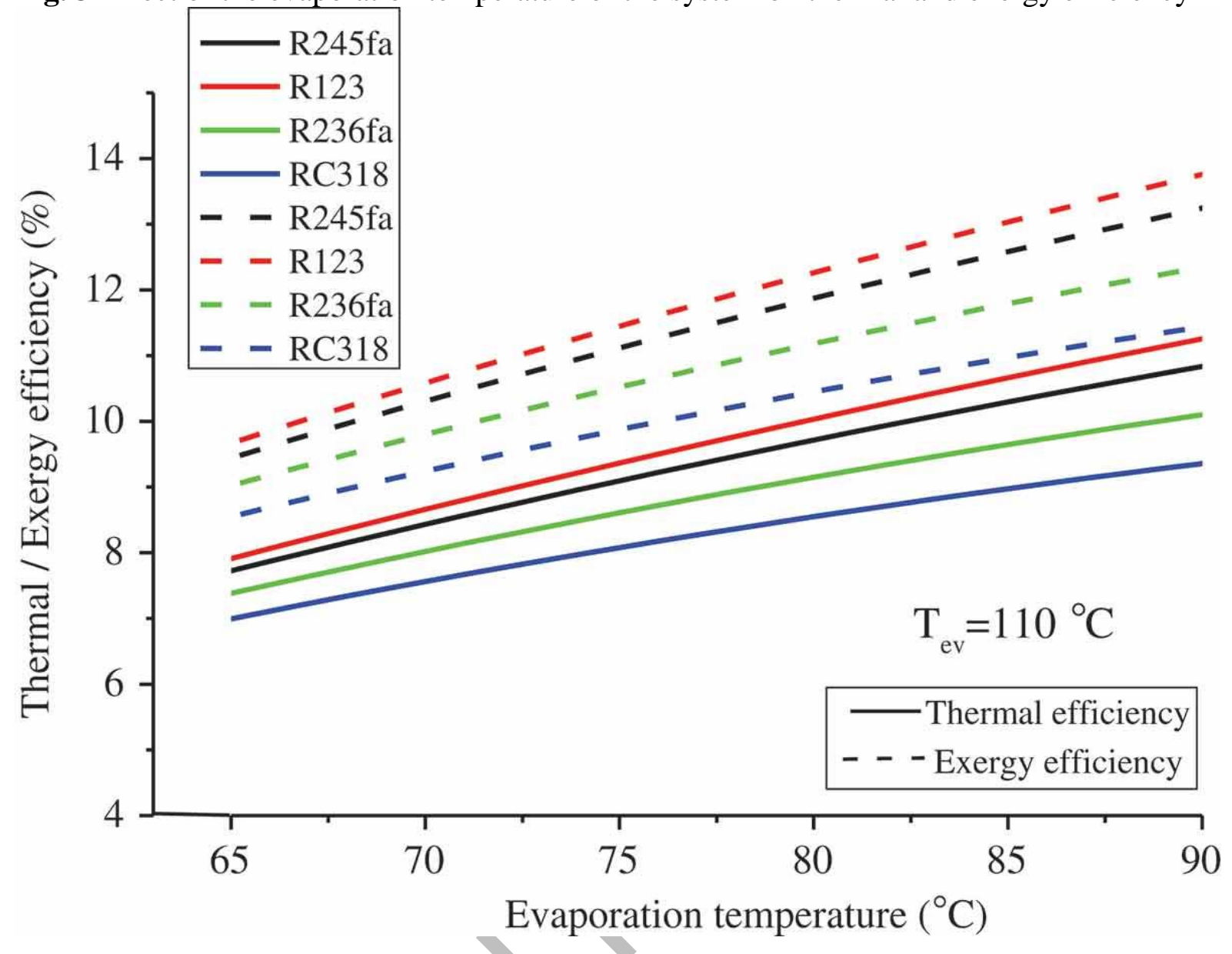


Fig. 4 Effect of the condensation temperature of the system on (a) thermal/exergy efficiency and (b) heating and electricity output
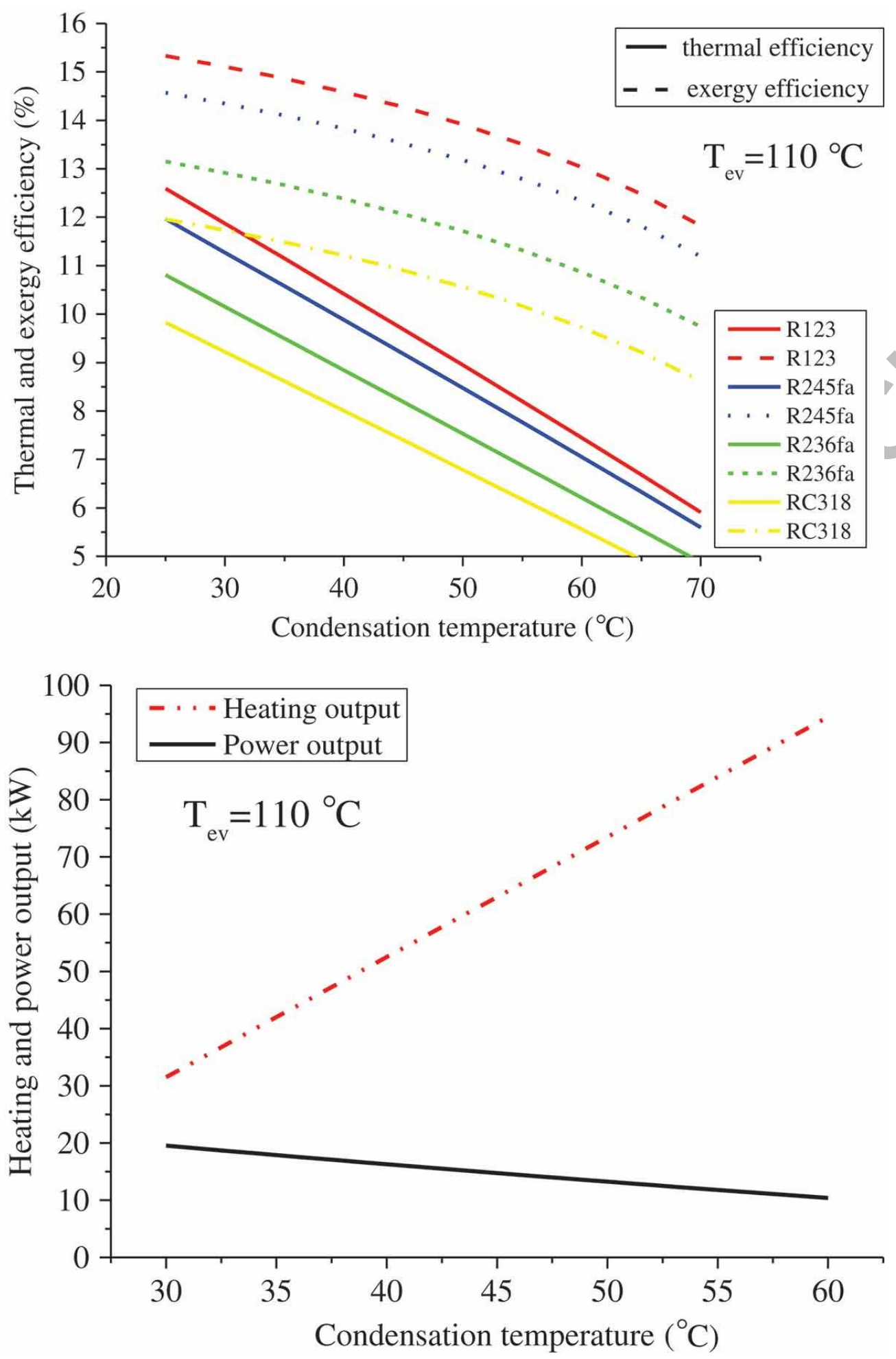
Fig. 5 The payback period of the investment as the function of the standard coal price

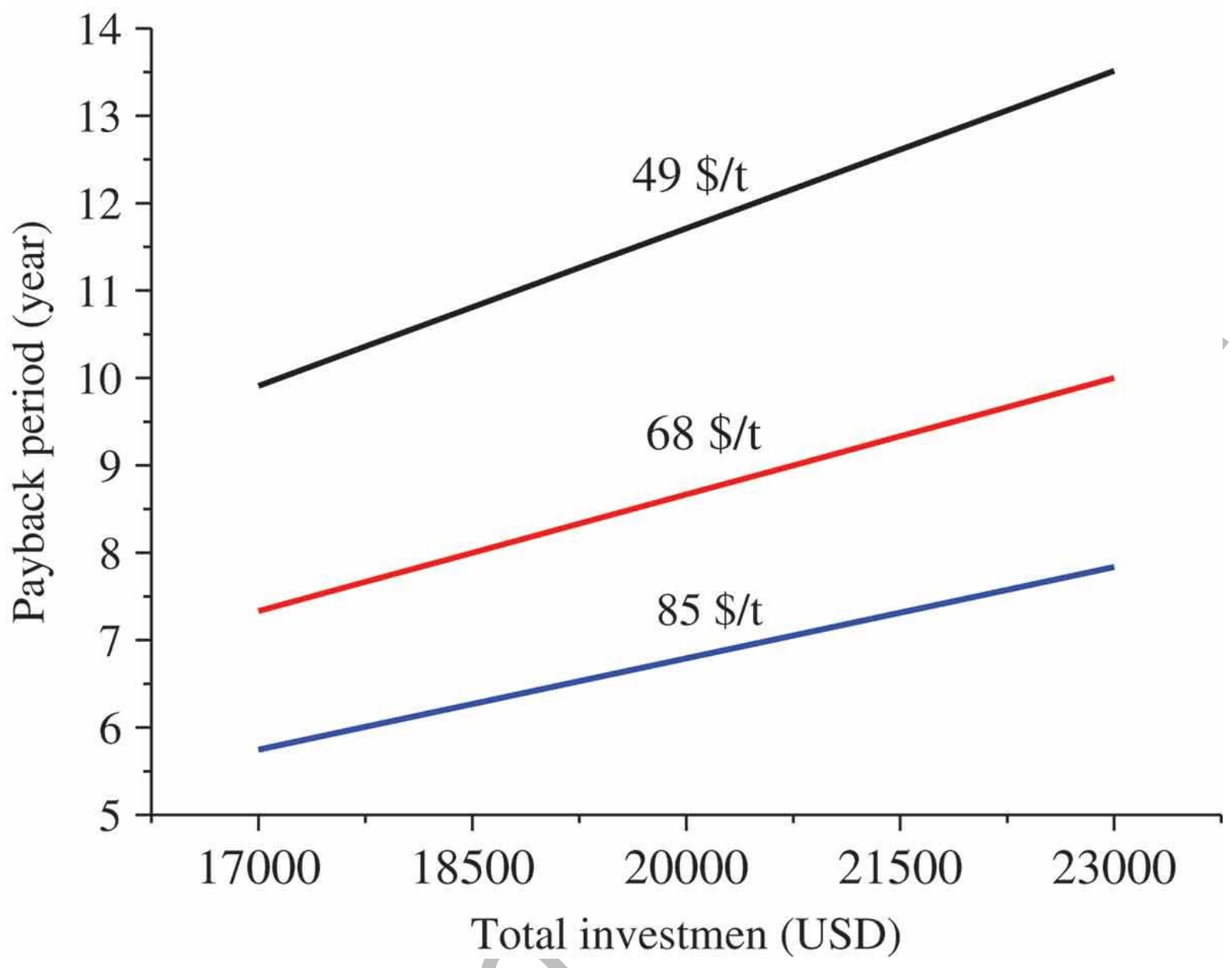

